\title{
Lower Segment Caesarean Section Audit Is a Promising Tool to Improve the Quality of a Standard Care at a Tertiary Hospital in Kuwait "Cross-Section Study"
}

\author{
Amina Nagy Elasy ${ }^{1,2^{*}}$, Sangeeta Dhawan², Lamiaa Lotfy El-Hawy ${ }^{3}$ \\ ${ }^{1}$ Obstetrics and Gynecology Department-Zagazig University Hospital, Zagazig, Sharkia, Egypt \\ ${ }^{2}$ Obstetrics and Gynecology Department at New Mowasat Hospital, Salmyia, Kuwait \\ ${ }^{3}$ Public Health and Community Medicine Community, Environmental and Occupational Medicine Department, Faculty of \\ Medicine, Zagazig University, Zagazig, Sharkia, Egypt \\ Email: ^aminanagy85@yahoo.com, sdhawan@newmowasat.com, lamiaa102elhawy@yahoo.com
}

How to cite this paper: Elasy, A.N., Dhawan, S. and El-Hawy, L.L. (2021) Lower Segment Caesarean Section Audit Is a Promising Tool to Improve the Quality of a Standard Care at a Tertiary Hospital in Kuwait "Cross-Section Study". Open Journal of Obstetrics and Gynecology, 11, 1665-1674. https://doi.org/10.4236/ojog.2021.1112156

Received: September 25, 2021

Accepted: December 13, 2021

Published: December 16, 2021

Copyright $\odot 2021$ by author(s) and Scientific Research Publishing Inc. This work is licensed under the Creative Commons Attribution International License (CC BY 4.0).

http://creativecommons.org/licenses/by/4.0/

(c) (i) Open Access

\begin{abstract}
Aim: Clinical audit is a tool to improve quality of care and to reduce maternal and perinatal morbidity and mortality. Auditing the CS according to a standard parameter will lead to strategies to avoid unnecessary intervention and to advice uniform practice. The aim was to evaluate the current practice and audit against international standards for various parameters relating to elective lower segment caesarean section and to assess compliance of physicians to audit standards. Subject and methods: This is a cross-sectional study which was in a tertiary hospital in Kuwait from $1^{\text {st }}$ October 2019 until $1^{\text {st }}$ October 2020. The hospital medical, electronic records and case notes of three hundred and twenty-six (326) cases of elective caesarean sections were reviewed for study participants. Those women were booked under the care of internal and external physicians. Demographic data and primary outcomes were collected. Results: Outcome was measuring the compliance to the recognized Caesarean Section international standards: consent form, grade of LSCS, antacid and anti-emetics, type of anesthesia, uses of antibiotics, umbilical cord blood $\mathrm{PH}$, and thromboprophylaxis. The compliance for a signed consent form and cord blood PH was (100\%), the use of preoperative antacid and antiemetic was (99.4\%), combined regional anesthesia was given in (53.4\%) of cases, preoperative antibiotics prophylaxis of second generation cephalosporin was to $(61.3 \%)$ of cases, post-operative thromboprophylaxis was given in (78.5\%) of cases of which (33.6\%) completed a 10 days duration. There was a statistically significant difference between internal and external physicians' compliance regarding, type of anesthesia 2.3 (95\% CI, $1.3-4.1, \mathrm{p}$
\end{abstract}


$=0.004)$, type and timing of antibiotics $0.42(95 \% \mathrm{CI} 0.22-0.79, \mathrm{p}=0.007)$ and $0.33(95 \% \mathrm{CI} 0.172-0.63, \mathrm{p}=0.0006)$ and thromboprophylaxis 8.1 (95\% CI $2.80-23.23, p=0.000)$. Conclusion: The results are encouraging, but suboptimal compliance is noticed mainly among external physicians.

\section{Keywords}

Audit, Quality, Lower Segment Caesarean Section, Tertiary Hospital, Kuwait

\section{Background}

Caesarean section has become a common major surgery in the practice of modern obstetrics with a considerable risk and a wide variety of morbidity. Clinical audit is a tool to improve quality of care and to reduce maternal and perinatal morbidity and mortality [1]. Audit plays an important role in the analysis of changing trends in caesarean delivery to be a more standardized procedure. The World Health Organization (WHO) recommends a rate of LSCS to be (5\% $15 \%)$ of all deliveries for any community and above which is considered unnecessary overuse of this procedure [2]. Medically justified caesarean section can effectively prevent maternal and perinatal mortality and morbidity. Caesarean section complications include [1] [2]: Infection, hemorrhage, complication of anesthesia, bladder injury, prolonged hospital stay and delayed recovery. In addition, caesarean delivery is associated with considerable costs for patients and hospitals, resulting in a longer hospital stay [3] [4] [5] [6]. A Standardized practice in the preoperative, intraoperative, and postoperative stings of caesarean section might help in reduction great part of untoward sequels of caesarean delivery. This can be done through implementing and auditing clear pathway for the procedure [4]. This cross-sectional study aims to assess the compliance to caesarean section pathway and its implications on the outcome of the procedure.

\section{Methods}

A cross sectional study was conducted at a large private hospital in Gulf accredited by Joint Commission International and Accreditation Canada International with around 2000 deliveries per annum. To maintain standards of care as per the established guidelines, audit of key interventions like elective lower segment caesarean section is done as part of our regular review cycle through the hospital Quality Systems Management Department. There is a practice guideline and pathway for caesarean section as required by JCI to ensure consistency of quality of care experienced by women undergoing caesarean section.

Medical files of all deliveries during period from 1 October 2019 until 1 October 2020 were reviewed. Eligible cases were recruited through ICD-10-CM (International Classification of Disease, Tenth Revision, and Clinical Modification).

Administrative approval: This study has the approval of medical director office as per local policy for such audit and publication. 
Inclusion criteria: Elective caesarean sections.

Exclusion criteria: Normal vaginal deliveries and emergency caesarean sections.

Sample size: (326 out of 2296 files) were following inclusion criteria.

These files were reviewed to check if they followed the audit standards, which considered as gold standards by RCOG guidelines, NICE guidelines and from the Kuwait Ministry of Health guideline.

The audit criteria were documented consent, grade of lower segment caesarean section, anti-emetic and antacid prophylaxis, antibiotic prophylaxis, type of antibiotic used and time of its administration, thromboprophylaxis, type of anesthesia and umbilical cord blood $\mathrm{PH}$.

Statistical analysis: Data were analyzed using the Statistical Package of Social Science (SPSS) program for Windows (Standard version 20). The normality of data was first tested with one-sample Kolmogorov-Smirnov test. Qualitative data were described using number and percent. Association between categorical variables was tested using Chi-square test while Fischer exact test was used when expected cell count less than 5 . Continuous variables were presented as mean \pm SD (standard deviation) for parametric data. Epi info 7 was used to calculate OR, odds ratio and $95 \% \mathrm{CI}$, confidence interval. The results were considered Significant when $\mathrm{P}$-value $\leq 0.05$.

\section{Results}

The total number of deliveries was 2296 cases out of which there were $\mathbf{3 2 6}$ cases of elective caesarean sections done. Regarding demographic data of studied population, mean age was $(31.4 \pm 4.9)$ years. Caesarean sections were done at gestational age equal or more than 38 weeks (49.7\%) (Table 1). Elective cesarean section was about (14.2\%) (Figure 1). Most common cause of LSCS was due to previous LSCS (64.4\%) (Figure 2).

Table 1. Demographics of studied population.

\begin{tabular}{lcc}
\hline \multicolumn{1}{c}{ Variables } & \multicolumn{2}{c}{ Study group $(\mathrm{n}=326)$} \\
\hline & Mean \pm SD & Min-Max \\
\hline Age (years) & $31.45 \pm 4.967$ & $21-46$ \\
weight (kg) & $85.19 \pm 14.222$ & $55-127$ \\
\hline Length of hospital stay (days) & $2.83 \pm 0.832$ & $2-7$ \\
Cord PH & $7.29 \pm 0.055$ & $7.08-7.43$ \\
\hline & No $(326)$ & 21.5 \\
\hline Parity: & 70 & 48.5 \\
PG & 158 & 30.0 \\
P1 - 2 & 98 & 50.3 \\
$>$ P2 & & 49.7 \\
\hline Gestational age & 164 & \\
$\bullet$ Less than 38 weeks & 162 & \\
$\bullet$ Equal or more than 38 weeks & & \\
\hline
\end{tabular}




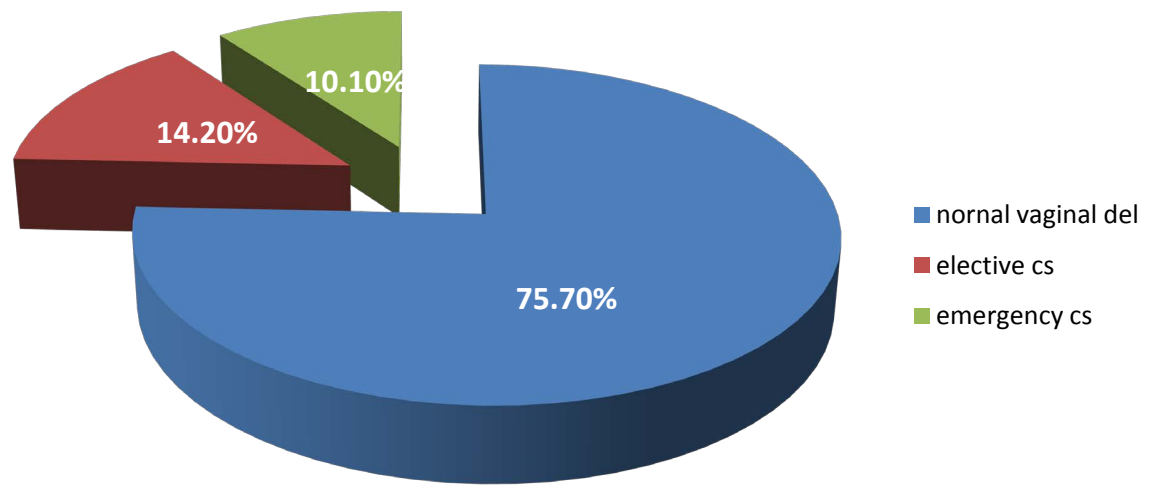

Figure 1. Pie chart diagram showing types of deliveries at New Mowasat Hospital.

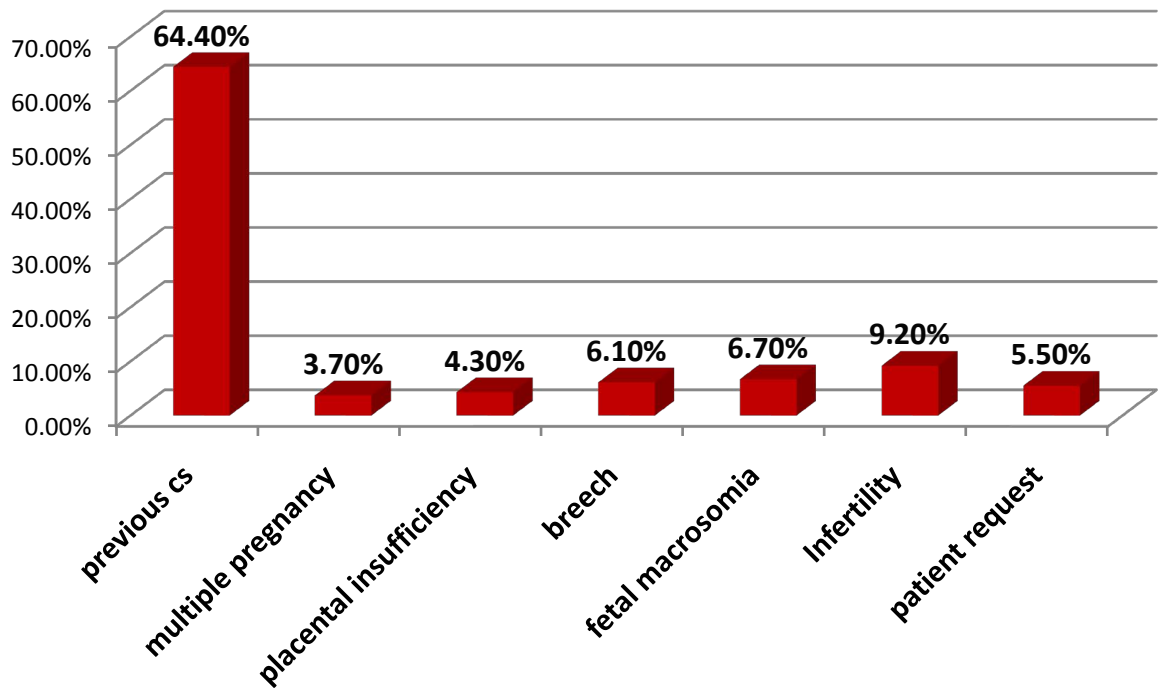

Figure 2. Bar chart showing the frequent causes of LSCS at New Mowasat Hospital.

In terms of auditable standards, total number of the studied sample was $(326 / 326)$ women, $(100 \%)$ of them signed the documenting consent form with appropriated grading of LSCS and were tested for cord blood PH. preoperative antacid and antiemetic 324 (99.4\%) and thromboprophylaxis was given in 256 (78.5\%), but those who completed a ten days' duration 86 (33.6\%). A second-generation cephalosporin used in 200 (61.3\%), however it was given before 60 mints of skin incision in 128 (39.3\%). A combined regional anesthesia was given in 174 (53.4\%) (Table 2).

There was statistically a significant difference between internal and external physicians regarding compliance to some LSCS audit standards. Internal physicians were more compliant than external physicians in giving combined regional anesthesia $\mathrm{OR}=2.3(95 \% \mathrm{CI}, 1.3-4.1, \mathrm{p}=0.004)$ and in giving thromboprophylaxis for 10 days OR $=8.1(95 \%$ CI $2.80-23.23, p=0.000)$ but external physicians were more compliant than internal physicians in giving 2 nd generation cephalosporin antibiotics $\mathrm{OR}=0.42(95 \% \mathrm{CI} 0.22-0.79, \mathrm{p}=\mathbf{0 . 0 0 7})$ before 60 mint of skin incision OR $=0.33(95 \%$ CI $0.172-0.63, \mathrm{p}=0.0006)($ Table 3$)$. 
Table 2. Compliance to the auditable standards.

\begin{tabular}{|c|c|c|}
\hline \multirow[t]{2}{*}{ Variables } & \multicolumn{2}{|c|}{ Study group $(n=326)$} \\
\hline & No & $\%$ \\
\hline Consent Complete & 326 & 100 \\
\hline Grad 4 urgancy & 326 & 100 \\
\hline Testing Cord PH & 326 & 100 \\
\hline \multicolumn{3}{|l|}{ Anesthesia: } \\
\hline \multicolumn{3}{|l|}{ Type } \\
\hline$\bullet$ general & 152 & 46.6 \\
\hline - combined regional & 174 & 53.4 \\
\hline \multicolumn{3}{|l|}{ Antibiotics: } \\
\hline $\begin{array}{l}\text { Type } \\
\text { - 2nd generation cephalosporin } \\
\text { - Others (Curam or Flagel) }\end{array}$ & $\begin{array}{l}200 \\
126\end{array}$ & $\begin{array}{l}61.3 \\
38.7\end{array}$ \\
\hline \multicolumn{3}{|l|}{ Duration } \\
\hline - Before 60 mint of skin incision & 128 & 39.3 \\
\hline - Within 60 mint of skin incision & 150 & 46.0 \\
\hline - After 60 mint of skin incision & 48 & 14.7 \\
\hline \multicolumn{3}{|l|}{ Thrombi prophylaxis: } \\
\hline \multicolumn{3}{|l|}{ Given: } \\
\hline - Yes & 256 & 78.5 \\
\hline$\bullet$ No & 70 & 21.5 \\
\hline $\begin{array}{l}\text { Duration: }(\mathrm{N}=256) \\
\text { - For } 10 \text { days } \\
\text { - Less than } 10 \text { days }\end{array}$ & $\begin{array}{c}86 \\
170\end{array}$ & $\begin{array}{l}33.6 \\
66.4\end{array}$ \\
\hline \multicolumn{3}{|l|}{ Taking antacids } \\
\hline - Yes & 324 & 99.4 \\
\hline - No & 2 & 0.6 \\
\hline \multicolumn{3}{|l|}{ Taking antiemetic } \\
\hline - Yes & 324 & 99.4 \\
\hline$\bullet$ No & 2 & 0.6 \\
\hline
\end{tabular}

Table 3. Relation between type of physicians and adherence to the audit standards.

\begin{tabular}{|c|c|c|c|c|c|c|}
\hline \multirow[t]{2}{*}{ Variables } & \multicolumn{2}{|c|}{$\begin{array}{l}\text { Internal } \\
(\mathrm{n}=266)\end{array}$} & \multicolumn{2}{|c|}{$\begin{array}{l}\text { External } \\
(\mathrm{n}=60)\end{array}$} & \multirow[t]{2}{*}{ COR $(95 \% \mathrm{CI})$} & \multirow[t]{2}{*}{ p-value } \\
\hline & $\mathrm{N}$ & $\%$ & $\mathrm{~N}$ & $\%$ & & \\
\hline \multicolumn{7}{|l|}{ Anesthesia: } \\
\hline \multicolumn{7}{|l|}{ Type } \\
\hline - General & 114 & 42.9 & 38 & 63.3 & & 0.004 \\
\hline - combined regional & 152 & 57.1 & 22 & 36.7 & & \\
\hline \multicolumn{7}{|l|}{ Antibiotics: } \\
\hline \multicolumn{7}{|c|}{ 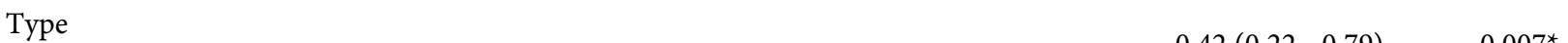 } \\
\hline - 2nd generation cephalosporin & 154 & 57.9 & 46 & 76.7 & $0.42(0.22-0.13)$ & \\
\hline - Others (Curam or Flagel) & 112 & 42.1 & 14 & 23.3 & & \\
\hline
\end{tabular}




\section{Continued}

\begin{tabular}{|c|c|c|c|c|c|c|}
\hline \multicolumn{7}{|l|}{ Duration } \\
\hline - Before 60 mint of skin incision & 94 & 35.3 & 34 & 56.7 & \multirow[t]{2}{*}{$0.33(0.172-0.63)$} & \multirow[t]{2}{*}{$0.0006^{* *}$} \\
\hline - Within 60 mint of skin incision & 134 & 50.4 & 16 & 26.7 & & \\
\hline - Before 60 mint of skin incision & 94 & 35.3 & 34 & 56.7 & \multirow{2}{*}{$0.72(0.33-1.62)$} & \multirow{2}{*}{0.434} \\
\hline - After 60 mint of skin incision & 38 & 14.3 & 10 & 16.7 & & \\
\hline \multicolumn{7}{|l|}{ Taking antacids } \\
\hline - Yes & 264 & 99.2 & 60 & 100 & UD & 1.000 \\
\hline - No & 2 & 0.8 & 0 & 0 & & \\
\hline \multicolumn{7}{|l|}{ Taking antiemetic } \\
\hline - Yes & 264 & 99.2 & 60 & 100 & UD & 1.000 \\
\hline$\bullet$ No & 2 & 0.8 & 0 & 0 & & \\
\hline \multicolumn{7}{|l|}{ Thrombiprophylaxis: } \\
\hline Given: & & & & & \multirow{3}{*}{$0.51(0.23-1.12)$} & \multirow{3}{*}{0.089} \\
\hline - Yes & 204 & 76.7 & 52 & 86.7 & & \\
\hline \multirow[t]{2}{*}{ - No } & 62 & 23.3 & 8 & 13.3 & & \\
\hline & $\mathrm{N}=204$ & $\%$ & $\mathrm{~N}=52$ & $\%$ & & \\
\hline \multicolumn{7}{|l|}{ Duration: $(\mathrm{N}=256)$} \\
\hline - For 10 days & 82 & 40.2 & 4 & 7.7 & $8.1(2.80-23.23)$ & $0.000^{* *}$ \\
\hline - Less than10 days & 122 & 59.8 & 48 & 92.3 & & \\
\hline
\end{tabular}

CI: Confidence Interval; OR: odd ratio; ${ }^{*}$ : Statistically significant; ${ }^{* *}$ : Highly statistically significant; UD: undefined.

\section{Discussion}

\subsection{Main Findings}

There is a professional concern about the increasing rate of caesarean section. Clinical audit is a quality improvement process that seeks to improve patient care and outcomes through systematic review of care against explicit criteria and the implementation of change. Aspects of the structure, processes and outcomes of care are selected and systematically evaluated against explicit criteria [3] [4].

LSCS rate reported high in developed countries. In United States, the rate of LSCS was reported $31.1 \%$, which may be a consequent to increased advance in fetal monitoring regarding the presumed intra partum fetal comprise [5]. In addition, the Middle East area still is having a higher rate of LSCS, and Iran had recorded a high rate of LSCS $48 \%$ [7]. Despite deficiency in fetal monitoring facilities along with high level of litigation, this could push the physician to rush for caesarean delivery and the private practice is considered to be a window to the increased rates of the caesarean section worldwide. Conversely, in our institution the total delivery load was 2296 a year, $75.7 \%$ of those deliveries were vaginal deliveries, followed by $14.2 \%$ elective caesarean section and $10 \%$ emergency caesarean section which comes within the WHO recommended range 5\% $15 \%$ for an elective caesarean section [6].

In terms of elective cases, we started to audit them to highlight how our local practice is close to the recognized international standards. Our auditable stan- 
dards include:

1) Antacid and anti-emetics prophylaxis: should be administered prior to general or regional anesthesia to reduce the gastric volume, acidity, and the risk of aspiration pneumonitis [8] [9] [10] [11]. We achieved 99.4\% compliance against $100 \%$ of the auditable standard.

2) Umbilical cord blood PH: should be performed after all elective or emergent LSCS or suspected fetal compromise, to allow review of fetal wellbeing and guide ongoing care of the baby [10]. We achieved 100\% compliance against $100 \%$ of the auditable standard.

3) Thromboprophylaxis: A LSCS is a major factor for thromboembolic disease. The RCOG proposed a risk assessment profile for thrombosis and that prophylaxis should be based on that assessment. Women having a LSCS should be offered thromboprophylaxis for 10 days because they are at increased risk of venous thromboembolism up to 4 folds during postpartum period (4 - 6 in 10.000) [8] [12] [13] the overall achievement was $78.5 \%$, but we met the criteria of 10 days' duration in $33.6 \%$ of cases.

4) Type of anesthesia: Women who are having a LSCS should be offered regional anesthesia because it is safer, earlier recovery and results in less maternal and neonatal morbidity than general anesthesia [12]. The overall achievement was $53.4 \%$ of cases received regional and $46.6 \%$ of cases received general anesthesia. Against auditable standard 95\% of grade 4 LSCS should be under regional anesthesia [14].

5) Type and timing of antibiotics: Women should receive a prophylactic antibiotic at LSCS before the skin incision; to reduce the risk of maternal infection with no effect on the baby has been demonstrate [12]. Antibiotics should be effective against endometritis, urinary tract, and wound infections, such as second-generation cephalosporin (co-amoxiclave not recommended before skin incision [9]-[16]. A second-generation cephalosporin, as recommended per guideline, was received in $61.3 \%$ of cases. Additionally, it should be given before the skin incision to reduce the risk of surgical site infection that was done only in $39.3 \%$ of cases and within 60 minutes of skin incision in $46 \%$ of cases.

\subsection{Strength and Limitations}

The institution has an approved policy by JCI for caesarean section, which should be followed by all physicians practicing at our hospital. Presence of medical records system which is the safest, economic, and simple way used to analyze cesarean sections. Regular auditing of the overall health services, process, and structure, along with appraising the health professions will grant a safe standard practice.

However, the limitations of our audit process, that we are challenged by having external physicians who had their own convenience based on their experience. As a private hospital, we should maintain our revenue in a line with international standards. Consequently, the rate of postoperative complications like 
wound infection, readmission and thromboembolic complications was difficult to track because of the small number of sample size and most of complicated cases directed to Ministry of Health hospitals.

\subsection{Interpretation}

In this study $50.3 \%$ of patients undergone LSCS at a gestational age less than 38 weeks and $49.6 \%$ at more than 38 weeks. Prim gravida women contribute largely to a caesarean decision. There are social reasons related to local community, the patients tend to specify their date of delivery especially in private hospitals. Therefore, we are in need to work more on patient education through patient information leaflets.

Suboptimal achievement in type and timing of prophylactic antibiotic is due to some of physicians still are having a concern of trans-placental transmission and acquired antimicrobial resistance. Regarding shortage of thromboprophylaxis duration may be due to the long-standing old practice of some physicians who believe that thromboprophylaxis should be given during hospitalization period only, along with carrying a risk of bleeding. Misbelieves and community narratives still discourage the pregnant women to have a regional anesthesia during their deliveries. Additionally, reluctance to compliance to the recommended audit standards due to:

- External doctors cannot be enforced to change their practice.

- Resistance to the change among the local professionals or in organizational environment or team.

- Patient they may have preferences in care that make the implementation difficult.

Based on the audit results, the suggested plan to improve the clinical performance all through caesarean pathway is recommended.

\subsection{Recommendation and Area of Improvement}

- Standardization of practice among all physicians.

- Guideline's activation \& Reinforcement of the policy.

- Education of the staff, profession, patients.

- A re-audit to be undertaken after 1 year is planned. A multidisplinary approach with involvement of all stakeholders including the consumers, local audit department and obstetrics and gynecology department will be the way forward to achieve the change.

\section{Conclusion}

These results are encouraging in many areas which yet highlight the need of improvement in others like timing of antibiotics, use of regional anesthesia and duration of thromboprophylaxis as an identified substandard care factor. Our study findings suggest that CS audit is a very useful tool and, if well implemented, can improve the quality of care, patients' satisfaction, and harmonize 
practice among care providers.

\section{Acknowledgements}

We are grateful to quality department for their contribution in the audit process.

\section{Conflicts of Interest}

The authors declare no conflicts of interest regarding the publication of this paper.

\section{References}

[1] Dekker, L., Houtzager, T., Kilume, O., Horogo, J., van Roosmalen, J. and Nyamtema, A.S. (2018) Caesarean Section Audit to Improve Quality of Care in a Rural Referral Hospital in Tanzania. BMC Pregnancy and Childbirth, 18, 164. https://doi.org/10.1186/s12884-018-1814-1

[2] Liu, S., Liston, R.M., Joseph, K.S., Heaman, M., Sauve, R. and Kramer, M.S. (2007) Maternal Mortality and Severe Morbidity Associated with Low Risk Planned Cesarean Delivery versus Planned Vaginal Delivery at Term. Cmaj, 176, 455-460. https://doi.org/10.1503/cmaj.060870

[3] Mbaye, M., Gueye, M., Gueye, M.D.N., Niang, N.K.S. and Moreau, J.C. (2015) Analysis of Cesarean Section Rate According to Robson's Classification in an Urban Health Centre in Senegal. International Journal of Reproduction, Contraception, Obstetrics and Gynecology, 4, 1100-1102. https://doi.org/10.18203/2320-1770.ijrcog20150435

[4] Ansari, A., Baqai, S. and Imran, R. (2019) An Audit of Caesarean Section Rate Using Modified Robson Criteria at a Tertiary Care Hospital. Journal of the College of Physicians and Surgeons Pakistan, 29, 768-770. https://doi.org/10.29271/jcpsp.2019.08.768

[5] MacDorman, M.F., Menacker, F. and Declercq, E. (2008) Cesarean Birth in the United States: Epidemiology, Trends, and Outcomes. Clinics in Perinatology, 35, 293-307. https://doi.org/10.1016/j.clp.2008.03.007

[6] Souza, J.P., Gülmezoglu, A.M., Lumbiganon, P., Laopaiboon, M., Carroli, G., Fawole, B. and Ruyan, P. (2010) Caesarean Section without Medical Indications Is Associated with an Increased Risk of Adverse Short-Term Maternal Outcomes: The 2004-2008 WHO Global Survey on Maternal and Perinatal Health. BMC Medicine, 8, 71. https://doi.org/10.1186/1741-7015-8-71

[7] Yazdizadeh, B., Nedjat, S., Mohammad, K., Rashidian, A., Changizi, N. and Majdzadeh, R. (2011) Cesarean Section Rate in Iran, Multidimensional Approaches for Behavioral Change of Providers: A Qualitative Study. BMC Health Services Research, 11, 159. https://doi.org/10.1186/1472-6963-11-159

[8] Nelson-Piercy, C., MacCallum, P. and Mackillop, L. (2009) Reducing the Risk of Thrombosis and Embolism during Pregnancy and the Puerperium. Green-Top Guideline, (37a).

[9] Wee, M.Y.K., Brown, H. and Reynolds, F. (2005) The National Institute of Clinical Excellence (NICE) Guidelines for Caesarean Sections: Implications for the Anaesthetist. International Journal of Obstetric Anesthesia, 14, 147-158. https://doi.org/10.1016/j.ijoa.2004.09.008

[10] Tuuli, M.G., Stout, M.J., Macones, G.A. and Cahill, A.G. (2016) Umbilical Cord 
Venous Lactate for Predicting Arterial Lactic Acidemia and Neonatal Morbidity at Term. Obstetrics and Gynecology, 127, 674. https://doi.org/10.1097/AOG.0000000000001339

[11] Baker, P.N., McEwan, A.S., Arulkumaran, S., Datta, S.T., Mahmood, T.A., Reid, F., Aiken, C., et al. (2015) Obstetrics: Prepare for the MRCOG: Key Articles from the Obstetrics, Gynaecology \& Reproductive Medicine Journal. Elsevier Health Sciences, Amsterdam.

[12] Nishimura, R.A., Otto, C.M., Bonow, R.O., Carabello, B.A., Erwin, J.P., Fleisher, L.A. and Rigolin, V.H. (2017) AHA/ACC Focused Update of the 2014 AHA/ACC Guideline for the Management of Patients with Valvular Heart Disease: A Report of the American College of Cardiology/American Heart Association Task Force on Clinical Practice Guidelines. Journal of the American College of Cardiology, 70, 252-289. https://doi.org/10.1016/j.jacc.2017.03.011

[13] Friedman, A.M., Ananth, C.V., Lavery, J.A., Fleischer, A.A., Chazotte, C. and D’Alton, M.E. (2019) Implementing Obstetric Venous Thromboembolism Protocols on a Statewide Basis: Results from New York State's Safe Motherhood Initiative. American Journal of Perinatology, 36, 574-580. https://doi.org/10.1055/s-0038-1668549

[14] Roberts, J.M. (1999) Obstetric and Gynecological Anaesthesia. Obstetrics \& Gynecology, 94, 978-984.

[15] Lamont, R.F., Sobel, J.D., Kusanovic, J.P., Vaisbuch, E., Mazaki-Tovi, S., Kim, S.K. and Romero, R. (2011) Current Debate on the Use of Antibiotic Prophylaxis for Caesarean Section. BJOG: An International Journal of Obstetrics \& Gynaecology, 118, 193-201. https://doi.org/10.1111/j.1471-0528.2010.02729.x

[16] National Institute for Health and Clinical Excellence (2014) Intrapartum Care for Healthy Women and Babies: NICE Clinical Guidelines.

\section{List of Abbreviation}

Lower segment caesarean section (LSCS) 